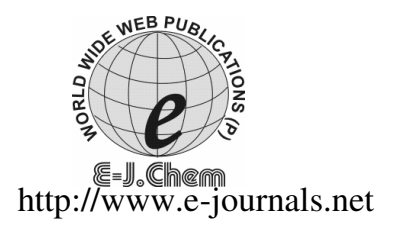

\title{
Spectrophotmetric Determination of Cefadroxil in Bulk and Dosage Form Using Sodium Hydroxide
}

\author{
S. W. SHANTIER* ${ }^{*}$ E. A. GADKARIEM, \\ K. E. IBRAHIM and H. A. EL-OBEID ${ }^{\S}$ \\ Department of Pharmaceutical Chemistry, Faculty of Pharmacy \\ University of Khartoum, Sudan \\ ${ }^{\S}$ Department of Pharmaceutical Chemistry \\ University of Medical Sciences and Technology, Sudan \\ sshantier@yahoo.com
}

Received 31 August 2010; Accepted 24 November 2010

\begin{abstract}
A simple spectrophotometric method was developed for the determination of cefadroxil in pure bulk and in capsules forms. The method is based on a direct reaction between cefadroxil and sodium hydroxide $(1 \mathrm{~N})$. A product with $\lambda_{\max }$ at $342 \mathrm{~nm}$ and molar absorptivity of $7.9 \times 10^{3} \mathrm{~L} \mathrm{~mol}^{-1} \mathrm{~cm}^{-1}$ is formed after heating cefadroxil with sodium hydroxide $(1 \mathrm{~N})$ for 30 minutes. The absorbance-concentration plot was rectilinear over the range $5-25 \mu \mathrm{g} / \mathrm{mL}$ with correlation coefficient values not less than 0.999 . The detection limit (LOD) and quantification limit (LOQ) were $0.693 \mu \mathrm{g} / \mathrm{mL}$ and $2.31 \mu \mathrm{g} / \mathrm{mL}$. The method was validated using the BP liquid chromatographic method for cefadroxil assay. The results obtained by the developed method for the capsules dosage form were statistically compared with those of the BP liquid chromatography method and evaluated at $95 \%$ confidence limits.
\end{abstract}

Keywords: Determination, Spectrophotometry, Liquid chromatography, Sodium hydroxide, Cefadroxil.

\section{Introduction}

Cefadroxil (Figure 1), an orally active cephalosporin in clinical practice, belongs to the group of $\beta$-lactam antibiotics ${ }^{1}$. It is chemically designated as 5-thia-1-azabicyclo[4.2.0]oct-2ene-2-carboxylic acid, 7-[[amino(4-hydroxyphenyl)acetyl]amino]-3-methyl-8-oxo-, monohydrate. Its antibacterial activity is dependent on the presence of the $\beta$-lactam functionality that can be hydrolyzed under aqueous conditions ${ }^{2}$.

Numerous analytical procedures have been reported for the determination of cefadroxil in its pure form, pharmaceutical preparations and biological fluids. The methods reported for 
the quantitative determination of cefadroxil in pharmaceutical formulations and biological fluids include spectrophotometry ${ }^{3-9}$, a chemiluminescence method using flow injection analysis $^{10}$, HPLC methods ${ }^{11-14}$ and oxidative method ${ }^{15}$.

The aim of the present work is to investigate the behaviour of cefadroxil upon alkaline hydrolysis in an attempt to develop a simple UV spectrophotometric procedure for determining cefadroxil in bulk and pharmaceutical forms by means of its hydrolysis product.

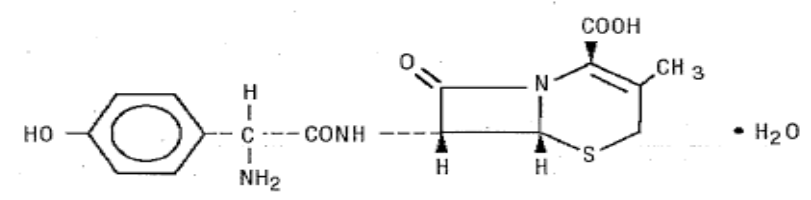

Figure 1. Structural formula of cefadroxil monohydrate

\section{Experimental}

All materials and reagents used were of analytical grade. Cefadroxil authentic material (M. Wt 363 and 100\% claimed purity) was supplied by European Pharmacopeia. Cefadroxil containing formulations (Midroxil ${ }^{\circledR} 500 \mathrm{mg}$ capsules MFG 6/08, exp. 6/11) manufactured by Middle East Pharmaceutical Company (MIDPHARMA), Jordan. Longicef $^{\circledR} 500 \mathrm{mg}$ capsules (MGF 8/07, exp. 8/10) manufactured by Kahira Pharm, Eygpt. Ibidroxil ${ }^{\circledR} 500 \mathrm{mg}$ (capsules, MGF 3/08, exp. 3/10) manufactured by GlaxoSmithKline, S.A.E. Sodium hydroxide, (BDH), Poole, England. Acetonitrile, Hipersolv( $\left.{ }^{\mathrm{TM}}\right)$, BDH, Poole, England.

\section{Apparatus}

JASCO V-530 UV Vis spectrophotometer, Kyoto, Japan. Water bath, gesellschaft fur labortechnik mbH, Germany. Balance, Kern ALS 120-4, Germany. Waters 600 liquid chromatograph with waters 2996 detector and enpower integrator. Wavelength $254 \mathrm{~nm}$.

\section{Column and mobile phase}

A fixed loop injector (Rheodyne, $20 \mu \mathrm{L}$ ) was used to transfer the sample into the column (Varians, C18, $4.6 \mathrm{~mm} \times 25 \mathrm{~cm}, 5 \mu \mathrm{m}$ ). The mobile phase consisted of a mixture of 4 volumes of acetonitrile and 96 volumes of a $2.72 \mathrm{~g} / \mathrm{L}$ solution of potassium dihydrogen phosphate $R$. Flow rate $1.0 \mathrm{~mL} /$ minute.

\section{Standard stock solution}

A stock solution of cefadroxil $(0.05 \%, \mathrm{w} / \mathrm{v})$ was prepared in distilled water. Ten $\mathrm{mL}$ of this solution was diluted to $100 \mathrm{~mL}$ with distilled water $(50 \mu \mathrm{g} / \mathrm{mL}$, solution $\mathrm{A})$.

\section{Calibration graph}

Different accurately measured volumes (1-5 mL) of solution A were transferred into five stoppered glass tubes. Distilled water was added to make a volume of $5 \mathrm{~mL}$ in each tube. Sodium hydroxide $(1 \mathrm{~N}, 1 \mathrm{~mL})$ was added to each tube before heating at $100{ }^{\circ} \mathrm{C}$ for 30 minutes. After cooling, the volumes were transferred quantitatively into $10 \mathrm{~mL}$ volumetric flasks, adjusted to $10 \mathrm{~mL}$ with distilled water and mixed well before reading at $342 \mathrm{~nm}$ against the appropriate blank $(1 \mathrm{~mL}$ of $1 \mathrm{~N} \mathrm{NaOH}$ diluted to $10 \mathrm{~mL}$ with distilled water). A graph was constructed by plotting the absorbance values versus drug concentrations in $\mu \mathrm{g} / \mathrm{mL}$ or these values were computed to obtain a regression analysis data for the graph. 


\section{Procedure for capsules}

Content of 20 capsules was calculated. An accurately weighed amount of the powdered sample equivalent to $0.05 \mathrm{~g}$ cefadroxil was transferred into a $100 \mathrm{~mL}$ volumetric flask and shaken with about $70 \mathrm{~mL}$ distilled water for 15 minutes. The volume was then completed to $100 \mathrm{~mL}$ with distilled water, mixed and filtered.

For the determination of capsules content, solution of the sample similar to solution A was prepared and labeled as solution B. A $3 \mathrm{~mL}$ volume of solution B was then treated as under calibration graphs. A graph was also constructed from solution B, similar to the reference solutions graph, to compare the slopes of these graphs as another means for capsules content determination.

\section{Optimization of heating time on the product formation and consistency}

Calibration graph procedure described was repeated using $5 \mathrm{~mL}$ accurately measured volume and varying the heating time with sodium hydroxide (15, 30, 45 and 60 minutes). The results obtained were recorded. The effect of heating time was assessed through maximum absorbance intensity.

\section{Results and Discussion}

The present study is intended to develop a simple, rapid and accurate spectrophotometric method for the determination of cefadroxil in pure form and pharmaceutical formulation. The cephalosporins are among the widely used antibiotics used for the treatment of bacterial infections in humans. Cefadroxil, one of these cephalosporins which belong to $\beta$-lactam group of antibiotics, is the target in the present study.

The importance of this group of antibiotics and the continuous introduction of new drugs of this series has encouraged many researches to try to develop such methods for their routine analysis. The quantitative alkaline hydrolysis of cefadroxil was utilized for its determination in its bulk and pharmaceutical formulation.

Figure 2 shows two well resolved bands for unhydrolysed cefadroxil with absorption maxima at $214 \mathrm{~nm}$ (peak A) and $264 \mathrm{~nm}$ (peak B) attributed to $\mathrm{O}=\mathrm{C}-\mathrm{N}-\mathrm{C}=\mathrm{C}$ - and $-\mathrm{C}=\mathrm{C}$ COO- groups found in cephalosporines ${ }^{16}$. Figure 3 shows the corresponding spectrum obtained after heating cefadroxil at $100{ }^{\circ} \mathrm{C}$ for 30 minutes. The peak at $264 \mathrm{~nm}$ (peak B) disappeared, as a result of $\mathrm{C}-\mathrm{N}$ bond cleavage in the four-membered amido ring. This behaviour is similar to degradation of all cephalosporins ${ }^{17,18}$. However, a new absorption peak at $342 \mathrm{~nm}$ (peak C) was observed in the UV absorption spectrum.

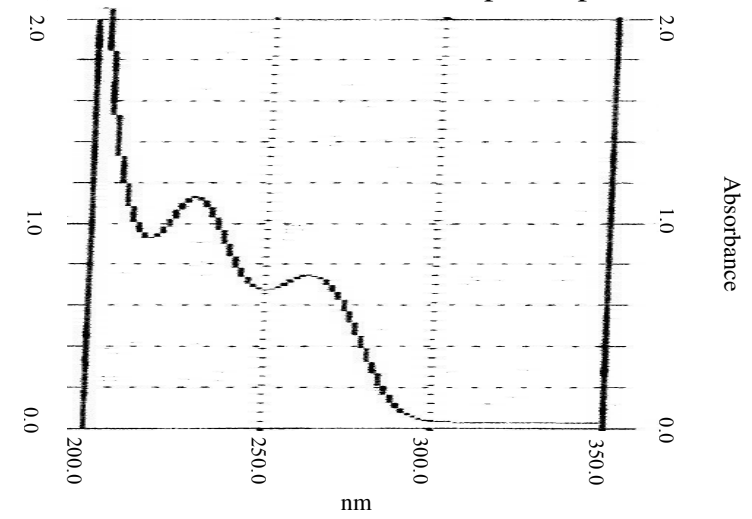

Figure 2. UV/VIS absorption spectrum of cefadroxil in water $(25 \mu \mathrm{g} / \mathrm{mL})$ 


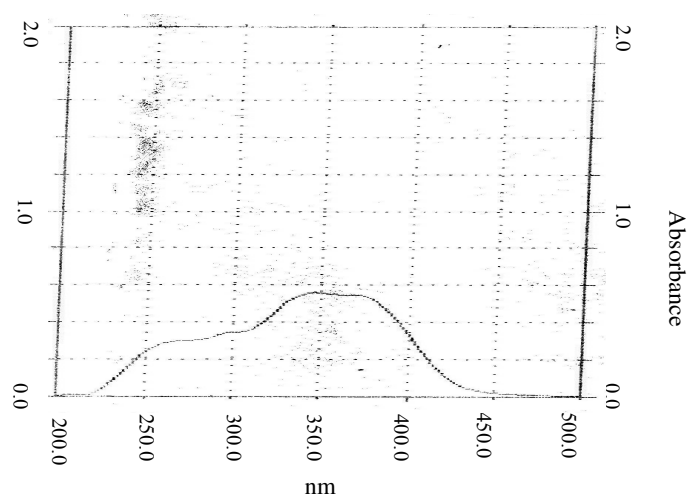

Figure 3. UV vis absorption spectrum of cefadroxil- $\mathrm{NaOH}$ reaction product $(25 \mu \mathrm{g} / \mathrm{mL})$

Factors like sodium hydroxide normality and volume coupled with the reaction time and temperature that can quantitatively hydrolyse the drug were studied and optimized. The results obtained for the heating time showed that heating with $1 \mathrm{~N} \mathrm{NaOH}$ for 45 minutes in boiling water bath gives higher absorbance and product formation. However, heating for 30 minutes was found to be the optimal condition to follow the degradation product with reproducible results (Table 1, Figure 4).

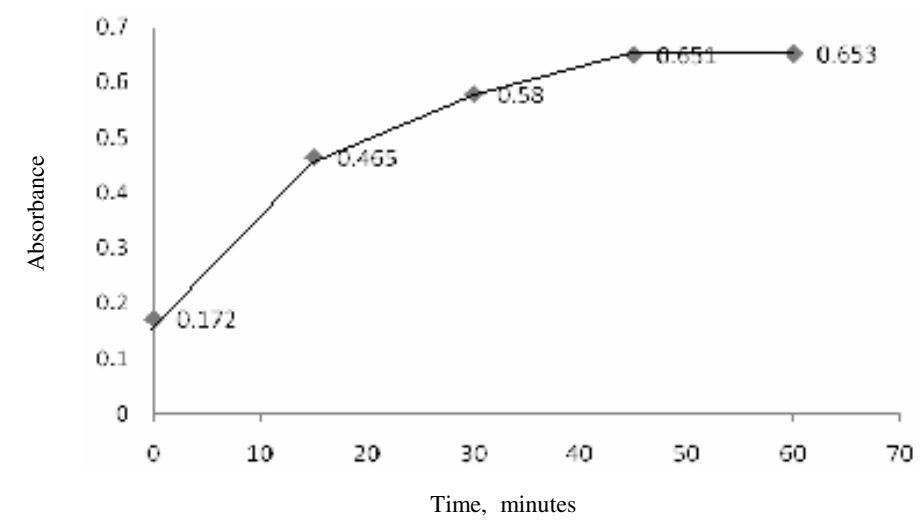

Figure 4. Absorbance of (cefadroxil-sodium hydroxide product) $v s$ heating time

Table 1. Estimation of cefadroxil- $\mathrm{NaOH}$ complex reaction time and stability

\begin{tabular}{lccccc}
\hline Heating time & 0 & 15 & 30 & 45 & 60 \\
\hline $\begin{array}{c}\text { Minutes } \\
\text { Absorption at } \\
\text { Wave length } \\
\quad 0.172\end{array}$ & 0.465 & 0.58 & 0.651 & 0.653 \\
$342 \mathrm{~nm}$ & & & & & \\
\hline
\end{tabular}

The formed product was found to remain stable for at least $24 \mathrm{~h}$. The optimized conditions were utilized to construct the calibration graph using authentic cefadroxil. Beer's law was obeyed for drug concentrations within a range of $5-25 \mu \mathrm{g} / \mathrm{mL}$. Spectral data for the reaction of sodium hydroxide with cefadroxil are presented in Table 2.

The low values of the standard deviations of the slope and correlation coefficient values (not less 0.999) reflected the consistency of the prepared calibration graphs. The limit of detection was calculated using the formula ${ }^{19}$ : 


$$
\mathrm{Y}_{\mathrm{B}}+3 \mathrm{~S}_{\mathrm{B}}
$$

Where $\mathrm{Y}_{\mathrm{B}}=\mathrm{a}$ (intercept value), $S_{B}=S y / x=0.00508$ (calculated from the regression analysis data, Table 2).

Table 2. Spectral data of the reaction of cefadroxil with sodium hydroxide

\begin{tabular}{cccccccc}
\hline $\begin{array}{c}\lambda_{\max } \\
\mathrm{nm}\end{array}$ & $\begin{array}{c}\text { Linearity } \\
\text { Range } \\
\mu \mathrm{g} / \mathrm{mL}\end{array}$ & $\begin{array}{c}\text { Limit of } \\
\text { quantification } \\
\mu \mathrm{g} / \mathrm{mL}\end{array}$ & $\begin{array}{c}\text { Limit of } \\
\text { detection } \\
\mu \mathrm{g} / \mathrm{mL}\end{array}$ & $\begin{array}{c}\text { Intercept } \pm \\
\text { std error }\end{array}$ & $\begin{array}{c}\text { Slope } \pm \\
\text { std error }\end{array}$ & $\begin{array}{c}\text { Correlation } \\
\text { coefficient }\end{array}$ & $\begin{array}{c}\text { Molar } \\
\text { absorptivity } \\
\mathrm{L} \mathrm{mol}^{-1} \mathrm{~cm}^{-1}\end{array}$ \\
\hline 342 & $5-25$ & 2.31 & 0.693 & $\begin{array}{c}0.009 \pm \\
0.005\end{array}$ & $\begin{array}{c}0.022 \pm \\
0.003\end{array}$ & 0.9993 & $7.9 \times 10^{3}$ \\
\hline
\end{tabular}

The value of $\mathrm{y}$ at limit detection was found to be 0.02424 . Using the regression analysis data $y=0.022 x+0.009$, yields limit detection of $0.693 \mu \mathrm{g} / \mathrm{mL}$. The limit of quantification is defined as the lower limit for precise quantitative measurement as opposed to qualitative detection. The value of $Y_{B}+10 S_{B}$ was used for this calculation ${ }^{20}$. The formula was applied in a similar way as for the LOD. The accuracy of the procedure and freedom of interference by the capsules excipients was confirmed by the results obtained for recovery testing of added amount of authentic cefadroxil to capsules solution in the ratio of 1:1. The calculation of added recovery was done using an adopted formula:

$$
\frac{A_{T}-A_{S m}}{A_{S t d}} \times 100
$$

Where $\mathrm{A}_{\mathrm{T}}=$ total absorbance of mixture (capsule solution + authentic solution) $\mathrm{A}_{\mathrm{Sm}}=$ absorbance of sample solution $\mathrm{A}_{\mathrm{Std}}=$ absorbance of authentic solution .

The results showed good recovery $(99.3 \% \pm 0.23, \mathrm{n}=2)$. The reproducibility for a concentration of $15 \mu \mathrm{g} / \mathrm{mL}$ was found to be $100 \% \pm 0.58, \mathrm{n}=3$. This reflected the precision of between-run replicates. The method was applied for the drug uniformity testing in cefadroxil $^{\circledR} 500 \mathrm{mg}$ capsules where good assay results $(\overline{\mathrm{X}} \pm \operatorname{RDS}(\%), \mathrm{n})$ were obtained $(99.6 \pm 0.012 \%, \mathrm{n}=3)$ (Table 3).

Table 3. Validation results of proposed method compared to the BP method (Liquid chromatography)

\begin{tabular}{lccc}
\hline & Content \% of cefadroxil & $\mathrm{t}^{*}$ cal, $\mathrm{t}(\mathrm{tab})$ & $\mathrm{F}^{*}$ cal, $\mathrm{F}(\mathrm{tab})$ \\
\hline & $\pm \mathrm{RSD} \%$ & & \\
Proposed method & $99.60 \pm 1.19 \% \mathrm{n}=3$ & $1.89(2.78)$ & $1.38(19)$ \\
BP liquid & $97.6 \pm 1.4 \% \mathrm{n}=3$ & & \\
Chromatography & & & \\
Method & & \\
\hline & ${ }^{*}=$ t and $F$ calculated and tabulated
\end{tabular}

The validity of the method for the determination of cefadroxil in bulk or pharmaceutical form was assessed by comparison of the statistical results obtained with those of the official BP liquid chromatography method. Data of Table 3 show the obtained assay results and the calculated $t$ - and $F$-values as compared to the corresponding tabulated values at $95 \%$ confidence level. As the calculated $t$ - and $F$-values were less than tabulated ones, the result 
of this method can be considered as accurate and precise as the liquid chromatography method. The developed method can be recommended for drug determination in quality control and routine analysis of the drug.

Capsules solutions prepared simulating the calibration graph $(5-25 \mu \mathrm{g} / \mathrm{mL})$, further confirmed the good assay results. The plots were almost superimposed on each other. The slopes were used to calculate the capsules content using the following formula:

$$
\frac{\text { Mean slope of sample graph }}{\text { Mean slope of authentic }} \text { X100 }
$$

This sample calibration graph can also be considered a useful indication of absence of interference by excipients (superimposed parallel graphs) as it uses a range of low to high concentrations of sample solution $(5-25 \mu \mathrm{g} / \mathrm{mL})$. Bulk and sample calibration graphs obtained for proposed method are shown in Table 4 . The bathochromic shift exerted by the formed product species may eliminate any possible interference.

Table 4. Bulk and sample calibration graphs results

\begin{tabular}{ccccc}
\hline & $\mathrm{R}$ & Slope & Intercept & $\begin{array}{c}\text { Average\% } \\
\text { recovery }\end{array}$ \\
\hline Standard & 0.9993 & 0.022 & $9 \times 10^{-3}$ & \\
Ibidroxil $^{\circledR}$ & 0.9992 & 0.022 & $9 \times 10^{-3}$ & $102.7 \pm 1.08$ \\
Midroxil $^{\circledR}$ & 0.9991 & 0.022 & $8 \times 10^{-3}$ & $99.6 \pm 1.19$ \\
Longicef $^{\circledR}$ & 0.9992 & 0.023 & $5 \times 10^{-3}$ & $101.1 \pm 0.25$ \\
\hline
\end{tabular}

HPLC study of the degradation of cefadroxil with $\mathrm{NaOH}$

This study was carried utilizing the BP liquid chromatography method. Figures (5a, 5b, 5c and 5d) illustrate typical chromatograms of degraded product after 30 minutes heating with $\mathrm{NaOH}(1 \mathrm{~N})$ processed at different wave lengths $(254 \mathrm{~nm}, 344 \mathrm{~nm}$ and $380 \mathrm{~nm})$. The HPLC, the separation tool, revealed a number of degradation products apparently with different chromophoric systems when monitored at these wave lengths. However for the developed UV method, it seems that a major product could be the one having a retention time of about 8 minutes (Figures $5 \mathrm{c}$ and 5d) monitored at $344 \mathrm{~nm}$ and $380 \mathrm{~nm}$.

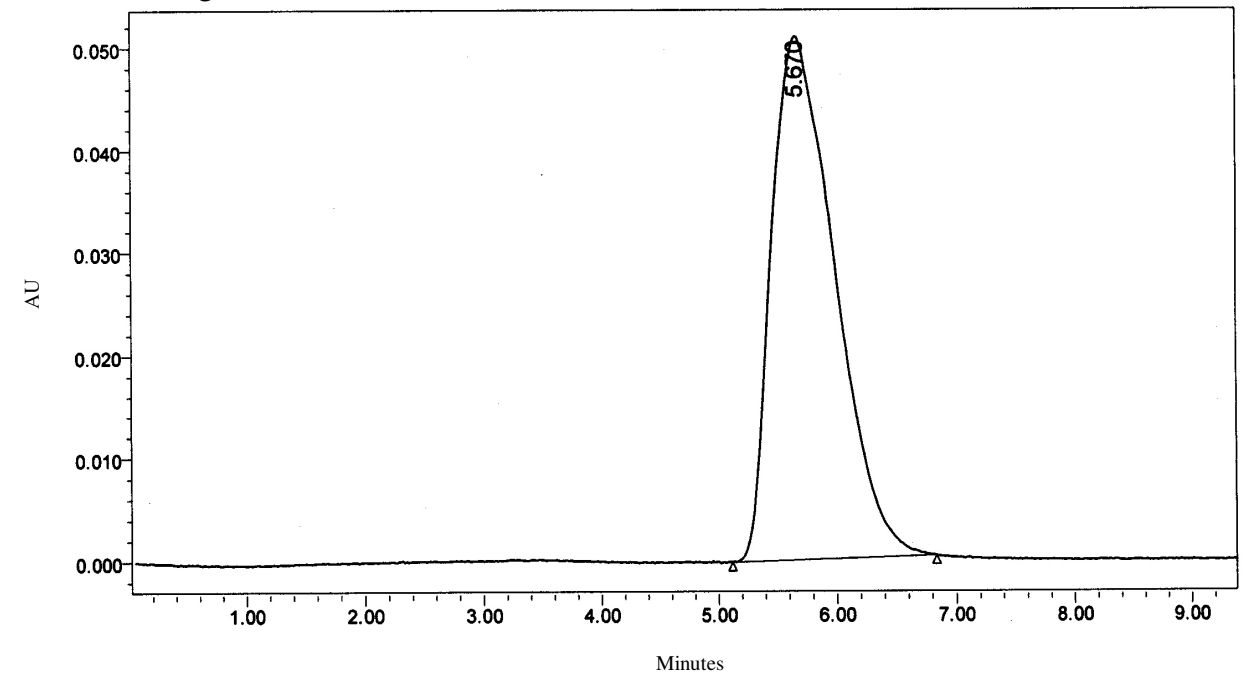

Figure 5a. Typical HPLC chromatogram of standard cefadroxil 


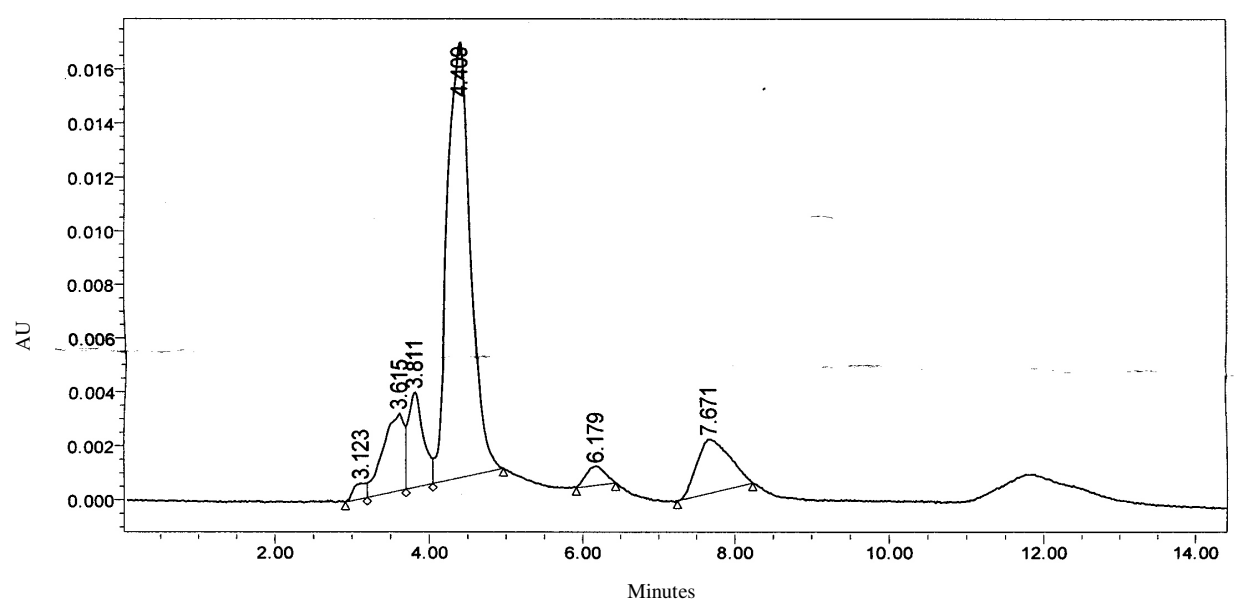

Figure 5b. Typical HPLC chromatogram of degraded product at wave length $254 \mathrm{~nm}$

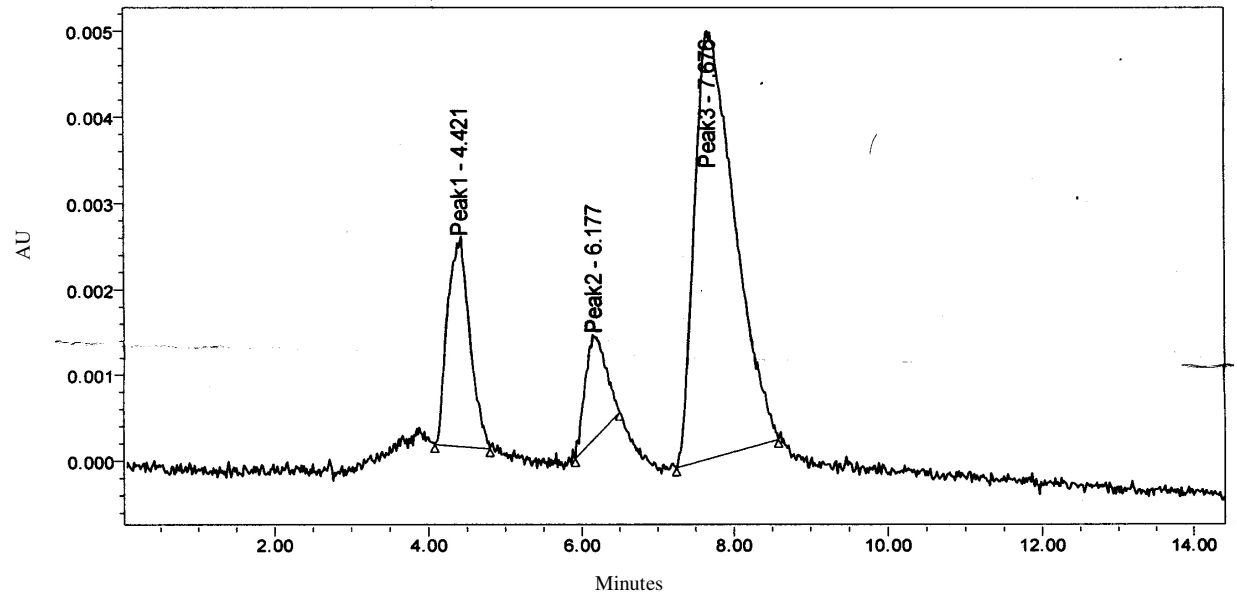

Figure 5c. Typical HPLC chromatogram of degraded product at wave length $344 \mathrm{~nm}$

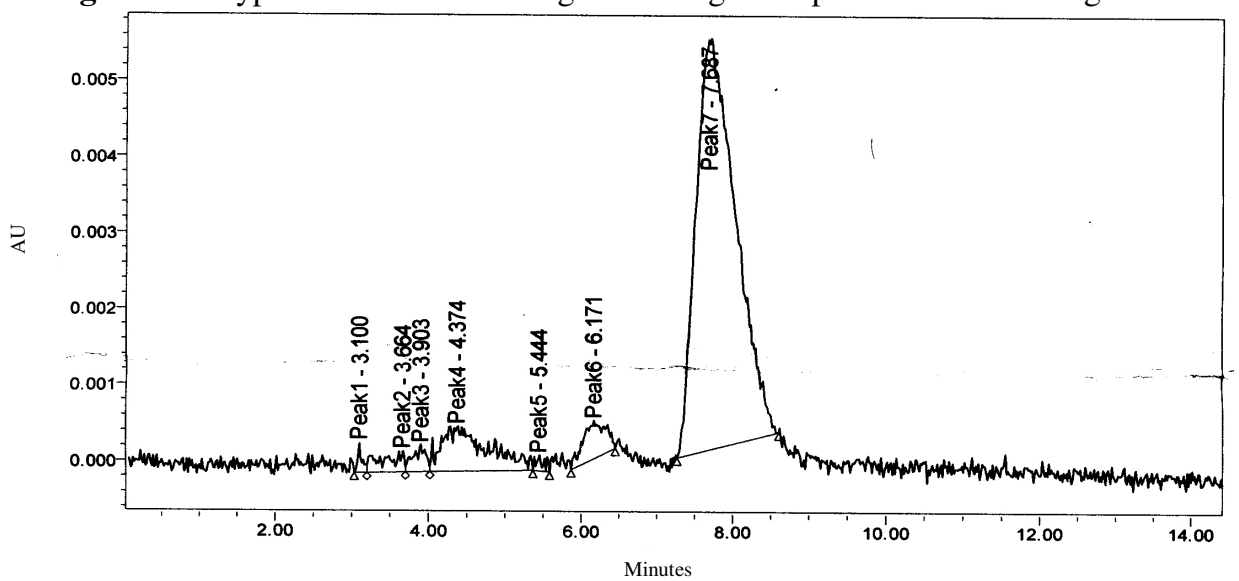

Figure 5d. Typical HPLC chromatogram of degraded product at wave length $380 \mathrm{~nm}$ 


\section{Proposed scheme for the alkaline hydrolysis of cefadroxil}

Some studies ${ }^{20}$ suggested that $\beta$-lactams with a free $\alpha$-amino function (e.g. cefaclor) form, under alkaline conditions, a cyclic 2,5-diketopiperazine derivative absorbing at about $340 \mathrm{~nm}$. The present study showed that treating cefadroxil with $1 \mathrm{~N} \mathrm{NaOH}$ produced a product absorbing maximally at $342 \mathrm{~nm}$ (Scheme 2). This indicates that cephalosporins with such similar structures (cefaclor and cefadroxil differ in the hydroxyl and chlorine groups), are expected to give alkaline hydrolysis products that can be utilized for the quantitative analysis of these drugs.

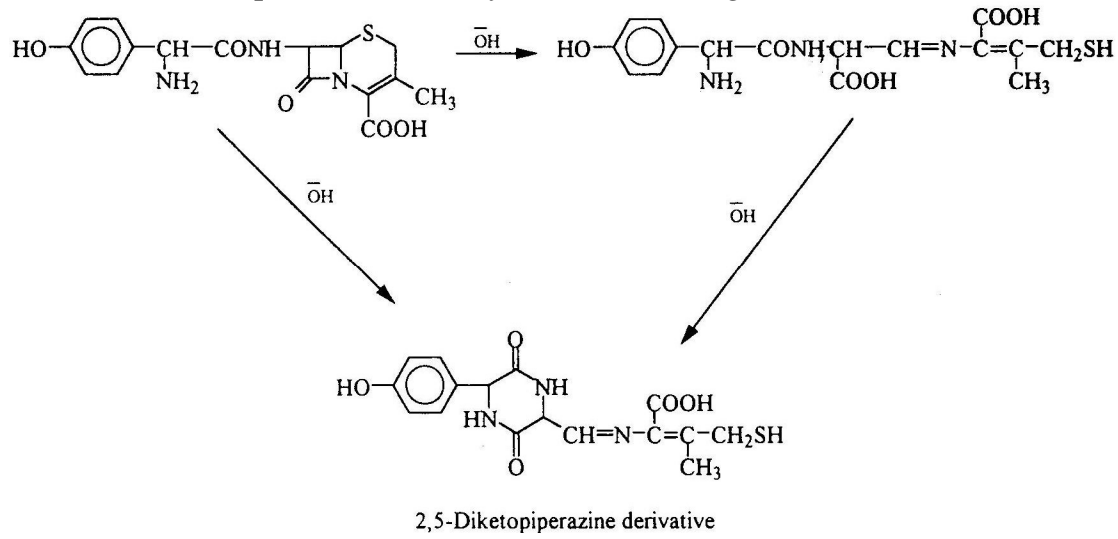

Scheme 2. Proposed mechanism for the reaction of cefadroxil and $\mathrm{NaOH}$

\section{Conclusion}

The above reported experimental results demonstrated that cefadroxil can be determined by means of its hydrolysis product, 2,5-diketopiperazine derivative, which produces a characteristic UV spectrum with a maximum absorption at $342 \mathrm{~nm}$.

The proposed method proved to be simple, economic, accurate and can therefore, be applied to the determination of cefadroxil in the pure form and in pharmaceutical preparations. The direct spectrophotometric method for cefadroxil does not find a practical application because of the lack of specificity, since all compounds containing $\beta$-lactam ring absorb in the range $250-270 \mathrm{~nm}$. On the other hand, the present method is selective for cephalosporins containing free $\alpha$-amino group. In addition, the major advantage of the proposed method is that the procedure does not require extraction step or great number of chemicals.

\section{References}

1. American Pharmaceutical Association; The United States Pharmacopeia, XXII, Washington DC, 1990.

2. Baertschi S W, Dorman D E, Occolowitz J L, Spangle A, Collins M W, Wildfeuer M E and Lorenz L J, J Pharm Sci., 1993, 82(6), 622-626.

3. Gamal A S, Analyst, 1996, 121, $641-645$.

4. Sastry C S P, Kolli Rama Rao and Prasad D S, Microchimica Acta, 1997, 126(1-2), 167-172.

5. Saadia M E, Fathalla B, Mohamed M E and Dalia R E, Microchimica Acta,2000, 135(3-4), 191-196.

6. Prodromos E, Analyst, 1989, 114, 237 - 239. 
7. Jirayu M, Suphachock U, Chalermporn T, Boonsom L and Saisunee L, Anal Sci., 2006, 22(4), 591-597.

8. Gamal A S, Hassan F A, Mohamed F R and Mahmoud A O, Talanta, 2001, 54(6), 1205-1215.

9. EL-Obeid H A, Gad-Kariem E A, Alrasheed K A, Al-Khamees H A, El-Shafie F S and Bawzeer G A M, Anal Let., 1999, 32(14), 2809-2823.

10. Fatma A A, Nawal A A and Abdulrahman A A, Talanta, 1998, 47(2), 471-478.

11. Shawky A F, J AOAC, 1998, 81(2), 381-385.

12. Shinde V M and Shabadi C V, Indian Drugs, 1997, 34(7), 399-402.

13. Patel Y P, Dhorda U J, Sundaresan M and Bhagwat A M, Indian Drugs, 1997, 34(1), 43-47.

14. Tai-Li T, Jing-Ran W and Teen-Meei W, J Chromatogr Rel Technol., 1996, 19(7), 1081-1095.

15. Hesham S and Gamal A S, J Pharm Biomed Anal., 2002, 28(6), 1205-1213.

16. Aly F A, Hefnawy M M and Belal F, Anal Lett., 1996, 29, 117-130.

17. Dimitrovska A, Stojanoski K and Dorevski K, Intern Pharm., 1995, 115, 175.

18. Lorens L J, Bachore F N and Olsen B A, J Chromatogr Sci., 1992, 30, 211.

19. Miller J C and Miller J N, Statistics and Chemometrics for Analytical Chemistry, Fifth Edition, 2005, 121-123.

20. Ivama V M, Rodrigues L N C, Guaratini C C I and Zanoni M V B. Spectrophotometric Determination of Cefaclor in Pharmaceutical Preparations, Quima Nova,1999, 22(2), 201-204. 


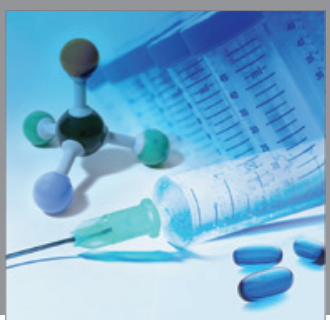

International Journal of

Medicinal Chemistry

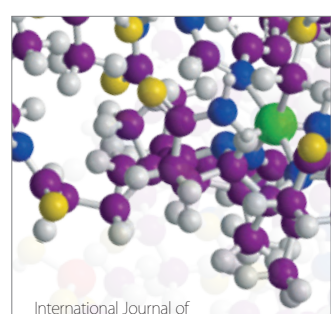

Carbohydrate Chemistry

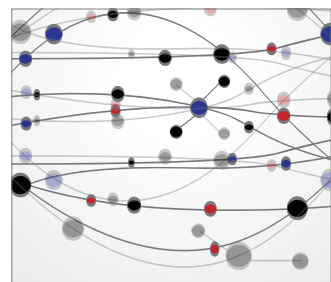

The Scientific World Journal
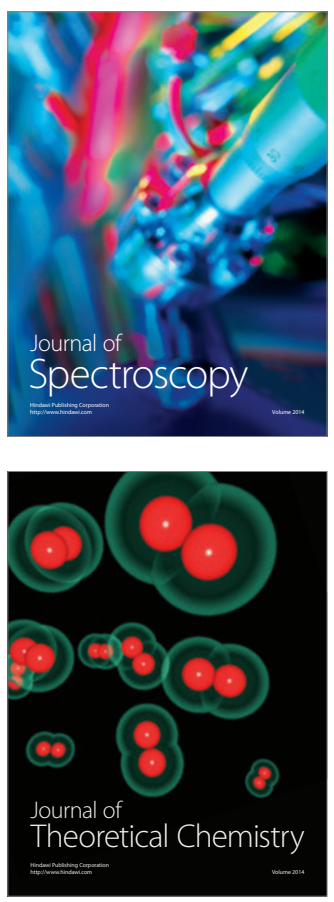
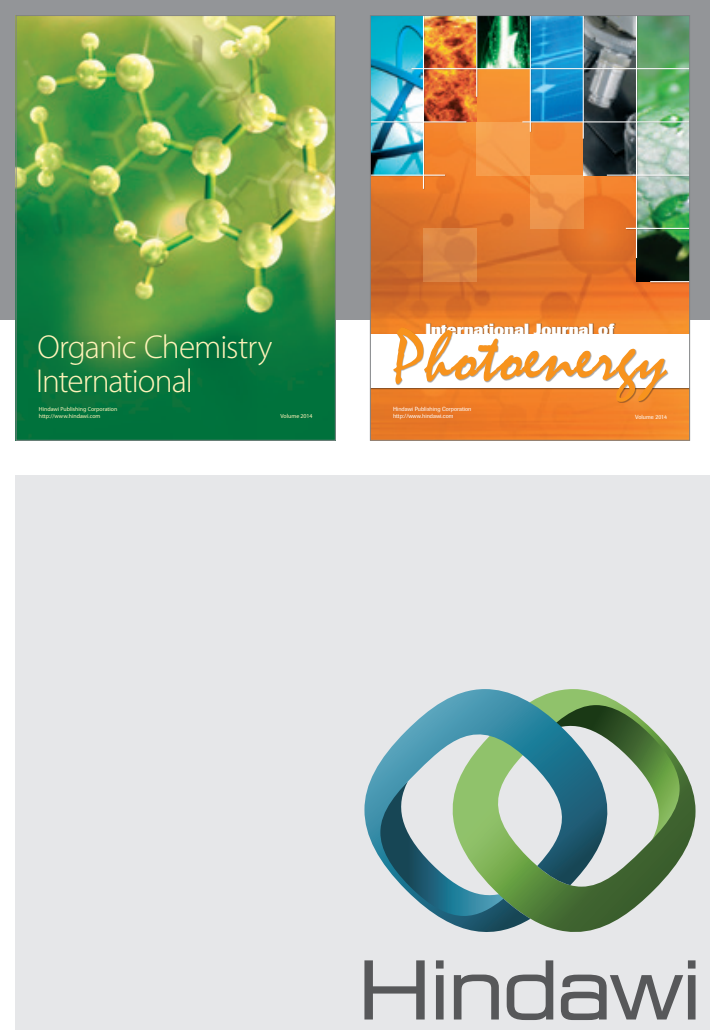

Submit your manuscripts at

http://www.hindawi.com
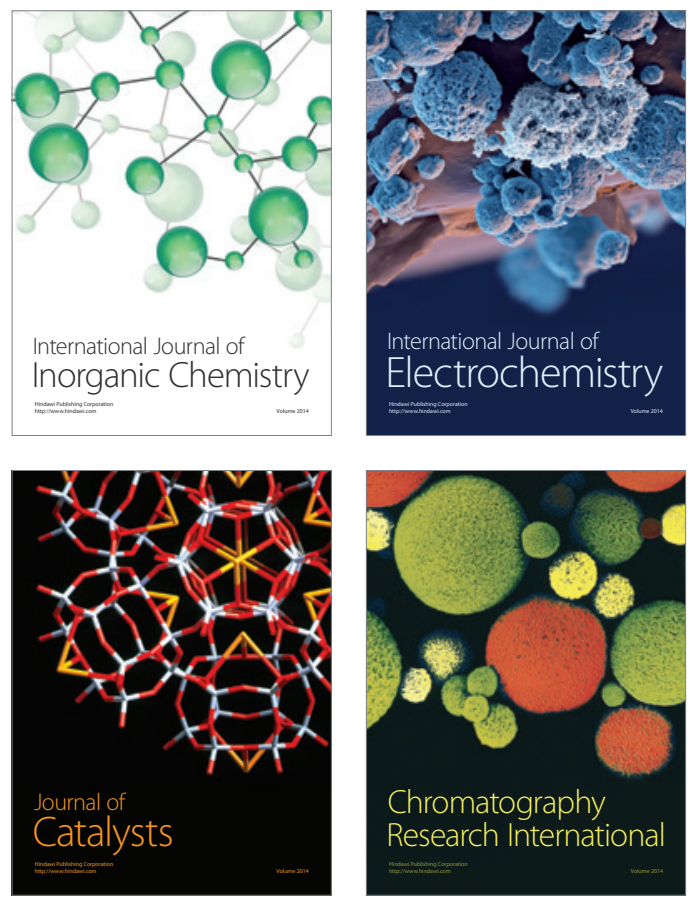
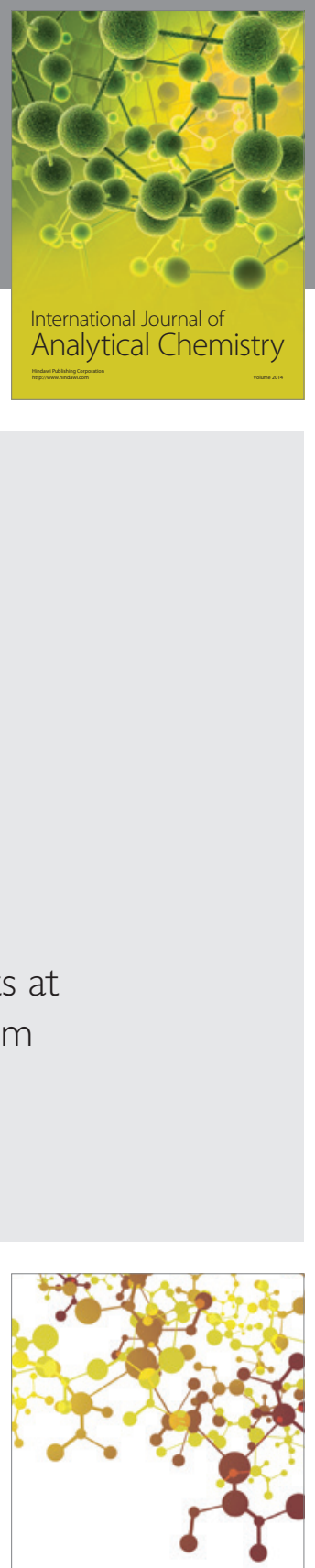

Journal of

Applied Chemistry
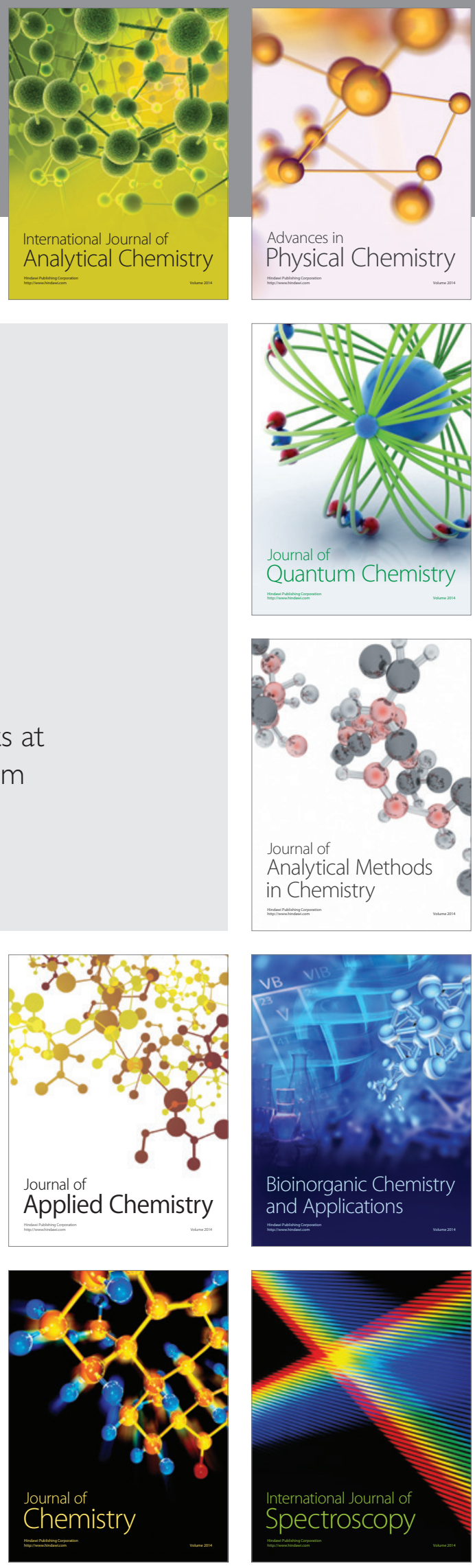